\title{
Reframing 'integration': acknowledging and addressing five core critiques
}

\author{
Sarah Spencer ${ }^{1^{*}}$ (D) and Katharine Charsley $^{2}$
}

\author{
* Correspondence: Sarah.spencer@ \\ compas.ox.ac.uk \\ ${ }^{1}$ Centre on Migration, Policy and \\ Society (COMPAS), University of \\ Oxford, 58 Banbury Road, Oxford \\ OX2 6QS, UK \\ Full list of author information is \\ available at the end of the article
}

\begin{abstract}
Empirical and theoretical insights from the rich body of research on 'integration' in migration studies have led to increasing recognition of its complexity. Among European scholars, however, there remains no consensus on how integration should be defined nor what the processes entail. Integration has, moreover, been the subject of powerful academic critiques, some decrying any further use of the concept. In this paper we argue that it is both necessary and possible to address each of the five core critiques on which recent criticism has focused: normativity; negative objectification of migrants as 'other'; outdated imaginary of society; methodological nationalism; and a narrow focus on migrants in the factors shaping integration processes. We provide a definition of integration, and a revised heuristic model of integration processes and the 'effectors' that have been shown to shape them, as a contribution to a constructive debate on the ways in which these challenges for empirical research can be overcome.
\end{abstract}

Keywords: Integration, Assimilation, Normativity, Methodological nationalism, heuristic model, Effectors

\section{Introduction}

Empirical and theoretical insights from the rich body of research on integration have led to increasing recognition of its complexity. From linear understandings of migrant assimilation, contemporary conceptualisations have become more nuanced and multifacetted. Analyses increasingly focus on integration as process rather than a Durkheimian end state, leading to greater understanding of temporal dimensions and to a focus on the significance of processes at the local level. It has become commonplace for European scholars to note that integration is 'two-way', involving both migrants and society at all levels (indeed 'three way' in recognition of transnational elements (Erdal and Oeppen 2013; Mugge 2016). Rather than a single process, integration has been examined as multiple processes taking place in differing domains (for which various groupings of economic, social and cultural 'dimensions' have been proposed). Relationships between these processes have been shown to be more varied than simultaneous.

There is, nevertheless, a lack of consensus on theoretical and methodological concepts, with divergent theoretical developments across disciplines and geography (Schneider and Crul 2010). 'Integration', as Entzinger and Biezeveld note, 'is often used

(c) The Author(s). 2021 Open Access This article is licensed under a Creative Commons Attribution 4.0 International License, which permits use, sharing, adaptation, distribution and reproduction in any medium or format, as long as you give appropriate credit to the original author(s) and the source, provide a link to the Creative Commons licence, and indicate if changes were made. The images or other third party material in this article are included in the article's Creative Commons licence, unless indicated otherwise in a credit line to the material. If material is not included in the article's Creative Commons licence and your intended use is not permitted by statutory regulation or exceeds the permitted use, you will need to obtain permission directly from the copyright holder. To view a copy of this licence, visit http://creativecommons.org/licenses/by/4.0/. 
as a term, but rarely defined as a concept' (Entzinger and Biezeveld 2003, p. 6); and empirical research often fails to reflect the conceptual developments that have been made. At the same time, criticism of the concept has focused on a failure in academic analyses to disentangle the normative ought from the empirical is; on the conceptualisation of migrants as 'other', and for idealised depictions of the society in which they live. As a consequence there has been a reluctance by some scholars to use the term, diverging into concepts such as inclusion and incorporation, with the result that there is a lack of coherence and clarity across the literature.

The Danish anthropologist Mikkel Rytter has argued (2018) that social scientists should go further and abandon the concept of integration all together. Indeed he suggests that the concept is so dangerous we should 'write against integration'. Rytter's is only one contribution to recent social scientific critiques of the way in which the concept is used in academic and policy discourses. These critiques, part of a broader call for greater reflexivity among migration scholars on the paradigms in which research is conducted (Dahinden 2016), centre on ways in which normative underpinnings combine with conceptual fuzziness to produce migrant-blaming depictions of social processes within distorted notions of nation states and homogenous majority populations within them.

These powerful arguments, while in turn the subject of reasoned critique (Penninx 2019), cannot be ignored. We argue that it may nevertheless be premature to jettison the concept of integration altogether. Rather, it is possible to address legitimate criticisms while retaining the term as the basis of theoretical and empirical scholarship, in preference to alternatives. It is profoundly important that we enhance understanding of the actual processes involved, for which we need to develop a common language and conceptual clarity. The time may be ripe, therefore, to 'renew' (Anthias and Pajnic 2014) or reframe the concept of integration in a way that responds to criticisms of the problematic ways in which it has often been used, and to reflect the 'state of the art' in terms of academic research findings. Building on conceptual developments in the field we argue that our heuristic model of integration processes can lend greater rigour to integration research and analysis. Applied as a tool, it can assist researchers to avoid the failings that critics of 'integration' have identified.

In the first section of this article we summarise the criticisms that scholars have made, drawing together, in the final part, the five core limitations that we agree need to be addressed. We apply those insights in the subsequent section which critiques the development of the concept, from assimilation through different models of integration, identifying limitations which remain to be addressed. We draw largely on European literature, differing approaches in US scholarship lying largely beyond the scope of this article. In the final section we explain how our own heuristic model can assist, if applied reflexively, to research design and analysis in this field.

\section{Writing against integration}

Critics argue that the concept of integration problematizes one section of the population as 'other', while simultaneously reproducing problematic imaginaries of society (as homogenous) and nation (as bounded). The term elides integration processes (what is happening) with normative notions of desired behavior and outcomes. The goal may be 
one which many share, as in Alba and Foner's seminal text comparing integration in the US and Europe, in which integration is defined as:

'the processes that increase the opportunities of immigrants and their descendants to obtain the valued 'stuff' of a society, as well as social acceptance, through participation in major institutions such as the educational and political system and the labor and housing markets. Full integration implies parity of life chances with members of the native majority group and being recognized as a legitimate part of the national community (Alba and Foner 2015, p. 5)'.

Nevertheless, integration used normatively, as Olwig and Paerregard write, 'is not a neutral concept denoting the joining together of different population groups'. Rather, it is 'ideologically loaded' (Olwig and Paerregard 2011, p. 2, cf. Fokkema and de Haas 2011, p. 8), bound up with ideologies of nationalism and constructions of belonging and inclusion. For Rytter it is part of the vocabulary of the nation state (Rytter 2018, citing Sayad 2004, p. 216ff). For Favell, the concept is also irredeemably connected with a top down nation building project which:

'sees supposedly self-contained European national societies coercing foreigners to behave more like prototypically (moral, acculturated, patriotic) nationals in the name of some fictitious national unity. It is, in other words, the political denial of the consequences of globalization on the $19^{\text {th }}$ century idea of the bounded nationstate-society' (Favell 2016, p. 2358).

The 'national container', as Dahinden puts it, 'remains the most important reference system for empirical research and theories' in migration and integration studies (Dahinden 2016). For Schinkel that context is the fiction of failed multicultural policies which has given license to problematize migrants. What people are supposed to integrate into is seldom questioned. 'Society' is: 'a bloodless, unmovable, undifferentiated, static concept devoid of everything a sociological concept should have' (Schinkel 2018, p. 7).

For Wieviorka the concept of society in the integration literature is one which reflects traditional sociological thinking - a Durkheimian, functionalist society: a bounded, integrated social system, inclusive of socialized individuals rather than the contemporary sociological imagination in which the implications, not least of globalization, and recognition of the local, have changed our understanding of people's lives and relations with others:

'the category of integration was appropriate at the time of Durkheim ... It has now become a nostalgic concept evoked by those who long to return to former times, to an age in which people could consider society as an entity or as a 'system', with its institutions, its state or its nation, while believing that all that remained to be done was to consider how individuals are socialized within this framework (Wieviorka 2014, p. 636)'.

This issue of normativity has serious ramifications for academic studies. Analytical use of the concept is undermined by the fact that it is also an emic term, with social and 
political meanings and consequences. Categories of analysis and of practice are conflated; 'integration' used for both. Normative ideas on preferred integration outcomes slip easily into academic models, preventing us posing the right scientific questions. We should, Crul and Schneider argue, be developing analytical models that seek to understand integration dynamics not to judge them (Crul and Schneider 2010, p. 1265).

For Anthias and Pajnic (2014), integration discourse is 'Janus-faced', purporting to concern the incorporation of migrants whilst actually contributing to their marginalisation by constructing particular migrant groups and their descendants as 'other' (unintegrated or unintegrateable), based on a narrow and homogenized projection of national belonging. It separates the deserving, well integrated (though still not one of us) from the undeserving who have failed to integrate, in analyses blind to the structural inequalities that can impede it as well as ignoring people's increasingly transnational lives. As Banton argues:

'When the governments of receiving societies perceive immigration as occasioning problems of national integration they often imply that it is the immigrantdescended population that has to change. This may be effective as political rhetoric, but before integration can ever become a viable sociological concept it will have to be possible to measure the degree to which all individuals, whatever their ethnic origin, are integrated (Banton 2008)'.

It is moreover not only migrants who experience marginalisation at the hands of integration discourses. Rather it is also applied to minorities who have no experience of migration, such as Roma (Magazzini 2020).

Schinkel notes, however, that white citizens have an 'integration dispensation': they are assumed to be integrated and thus not the focus of study (Schinkel 2018, p. 4). Critical analyses of integration discourses have indeed frequently revealed their exclusionary nature (Gedalof 2007; Rytter 2010; Olwig and Paerregard 2011), potentially contributing to the social divisions they purport to address. Integration is then not the solution but rather, in problematizing the relationship of immigrants to the rest of society, a significant part of the problem. Schinkel (2018) goes as far as to say that scholars who monitor integration are contributing to a neocolonial form of knowledge production, providing the factual architecture in which the problematisation of the migrant other takes shape, a judgement echoed by Favell in his commentary on Schinkel's work (2018).

Rytter's insightful discussion of the life of the term 'integration' in Danish contexts highlights the implications of the lack of any agreed conceptualisation of it. This leads to discursive slippages in the meaning of the term which facilitate the construction of particular groups and individuals as unintegrated. Hence, amid a focus on educational attainment as a marker of integration, when Danish Pakistani girls start to outperform their 'native' counterparts at school, this is portrayed not as a sign of their integration but as an indicator of overly strict parenting - in other words as a lack of sociocultural integration on the part of Danish Pakistani families. With no clarity on defining 'integration', it is in the eye of the beholder. As integration from this perspective is an 'empty signifier' (Laclau 1996 in Rytter 2018), changing meaning according to an (always politicised) context, 'enough is never enough' so that for those pre-constructed as unintegrateable, integration is a 'Sisyphean task' (Rytter 2018). 
For Rytter (2018), the answer is not for social scientists to remedy that lack of clarity but to 'write against integration'; to challenge this perspective and find new ways of writing about empirical processes. For Schinkel the questions is whether we want to make our resources as academics 'available for racist modes of relating to migrants and their children, or for alternatives' (Rytter 2018, p. 15). Schinkel's sharp criticism in particular has attracted firm rebuttals. While the critique that the concept of integration is unclear, and of normativity, are accepted, his 'sweeping interpretations' of integration scholarship are rejected (Penninx 2019; Hadj Abdou 2019), scholars confident that it is possible to conduct research on integration outside of the problematic discourse to which he refers. Moreover, failing to do so would leave the power inequalities and issues of membership that arise from migration, and the objectives of those who seek to 'manage' it, unstudied and unresolved (Klarenbeek 2019).

Penninx rightly argues that the concept of integration has fundamentally different functions in research and policy (critics might in turn argue that some scholars do not recognise that); and that Schinkel wrongly assumes that the function of integration research is to problematize migrant others. For Penninx there is no reason to advise against the use of integration as a concept 'as long as we have and use our independent, non-normative analytical concepts'; advocating the model he put forward with GarcésMascareñas in 2016 (below). Schinkel, he argues, ignores the work that has been undertaken, by Heckmann, Bommes and others, to develop comprehensive analytical concepts in which the notion of society, far from ignored, is central (Penninx 2019).

Klarenbeek, accepting that integration is indeed mostly conceptualised and measured as a process that only migrants go through, argues this can be addressed by conceptualising it as a process of boundary change in which all individuals are engaged. The direction of change is towards equality of social standing in their relationships - a concept she acknowledges is not stripped of normative content. It is, rather, a 'desirable outcome', addressing a form of injustice. Yet it demonstrates that it is possible to avoid Schinkel's 'integration dispensation' to non-migrants: the migrant is neither the focus nor the problem (Klarenbeek 2019).

\section{Five core critiques}

Notwithstanding those caveats, the critics have identified fundamental weaknesses that it is necessary to avoid in using a concept of integration - a challenge which some think cannot be met. We suggest instead that they point to prerequisites for a more sustainable approach. The responsibility is that of reflexivity, to identify and address each limitation rather than to abandon the endeavor. We identify from that literature five core critiques; five pitfalls to be avoided:

1. Normativity: First, critics have pointed to the need to address the normativity which pervades this field. The aim should be to study what is happening, the actual processes, not to prescribe or judge what ought to happen, the desired end goal. As a first step, the integration concept on which the research and analysis is based must not include (or must keep to the minimum achievable) any normative connotations on the desired end goal. We must then take a reflexive approach to the design of the research, and later the analysis of the data, to interrogate any assumptions on which it is based. 
2. Objectification of the 'other': Second, the concept must avoid reinforcing a sense of difference and separation, of migrants set apart and problematized as in 'need of integration'. It must contextualise individuals within not beyond society; reorienting the focus of study away from migrant populations towards the population as a whole (whether that be of a neighbourhood or on a larger scale), within which the significance of migration and/or ethnicity can be explored for the issue in question. Thus 'the research question loses its migration-specific focus while remaining sensitive to the role of migration and ethnicity in the phenomenon being investigated' (Dahinden 2016, p. 2218). Integration is seen as a process engaging all individuals, not only migrants.

3. Outdated imaginary of society: Related to this is the need to shift the focus to the dynamics of the whole society: not as an imaginary, homogenous, entity but as diverse, segmented (not least by class and structural inequalities), fluid and evolving; with porous internal and external boundaries. Society is not a bounded, stable, functional entity, disturbed at its margins by migration, but constantly in flux, shaped by the mobilities of people and ideas, and the ways in which they spatially interconnect, over time. Integration processes are thus open ended. There are no outcomes, only snapshots at any moment of time (Urry 2000, p. 18; Skrobanek and Jobst 2019). Society, at all its levels - individuals, collectives and institutions - needs to be studied as a powerful body of actors, indeed the dominant body of actors, that create opportunities and barriers for those who have newly arrived as well as for those who have never been away.

4. Methodological nationalism: It follows from that understanding of society that we need to incorporate the global and the transnational into our concept of the processes in which migrants and other residents are engaged. We need to conceptualise integration processes outside of a national paradigm, recognise the ephemerality of the borders of the nation state, and contemporary migration patterns of temporary and circular migration, as well as the transnational connections they maintain: individuals belong to and have a sense of belonging in more than one locality within and across international borders.

5. Narrow focus on migrants in factors shaping integration processes: Rather than focusing solely on factors related to migrants (such as their level of education and skills), the concept needs to capture the multiple and systemic factors which facilitate and impede processes of engagement over time. That recognition exposes the fallacy of attributing responsibility (or indeed blame) to any one party. Among the multiple factors impacting on integration processes it is also clear that, for individuals, those relating to the migration experience are only some of the factors at play. Many migrants, moreover, have family members without migration experience, with whom processes of integration are entwined (Charsley et al. 2020). There is a need to broaden recognition of the range of actors, and factors, involved.

Finally, we need clarity, a workable definition of integration that captures these elements of the concept.

Care then needs to be taken in academic discourse to use a language which reflects the concept used - to avoid terms such as 'the integration of migrants' which suggest a 
one way process of incorporation, or 'better integrated' which implies a normative goal. The challenge here is the often implied directionality of such processes - from less, to 'more integrated' - which itself implies a normative definition of 'integratedness'. Yet we know empirically that integration processes are not unidirectional - engagement can grow but also decline: through loss of employment, for instance, or a growing sense of alienation. Migrants may not, moreover, want to participate fully if in transit or intending only a temporary stay. It is not only that we cannot assume that 'integration' is always a feasible or desired goal but that the concept of an end goal is itself a normative construct (Wieviorka 2014, p. 637).

As Penninx noted of Schinkel, the critiques of integration focus on the uses of the integration concept rather than recent work to develop more robust models capable of empirical application. In the following section we review the development of those earlier models to consider the extent to which they met the challenges on which the critics focus, identifying some limitations that remain to be addressed.

\section{Evolution of a concept}

The engagement between migrants and the societies in which they live has been studied using a range of concepts: those of assimilation and acculturation before the concept of integration that is our focus. There are, notwithstanding equally severe critiques of those earlier concepts, certain lessons that can help us here.

\section{Lessons from assimilation studies}

Early twentieth century sociologists deployed the concept of assimilation to explain the changing relationship between immigrants and their country of residence. Initially it was seen as a one way process, largely of cultural adaption, into a homogenous majority society. The process was measured by how similar migrants had become to 'natives' in terms of their attitudes and behaviour, extending for some authors to labour market performance. Assimilation often referred, as would its successor, integration, both to the process in which immigrants were engaged and to a normative policy goal (Park and Burgess 1921; Entzinger and Biezeveld 2003).

Critics argued that the process is not only one of cultural change; is not one way; and is a process in which structural inequalities shape outcomes. Some scholars took that criticism on board, recognised a mutual process of change, that the 'receiving' society is itself diverse, and that retention of ethnic community ties can provide stepping stones towards economic participation. Segmented assimilation theory was developed in the early 1990 s to explain the trajectories of the children of immigrants into different socio-economic groups and their differing cultural but also economic and social outcomes. Economic opportunity structures and discrimination were identified as two of the significant causal factors (Portes et al. 2005). Nevertheless, within an assimilation framework there remained limited focus on structural dimensions of the process. A reliance by some authors on cultural determinism in explanations of poor outcomes, overstating the causal impact of culture relative to structure, was heavily criticised (Stepick and Stepick 2010; Schneider and Crul 2010, p. 1144).

Some scholars have nevertheless argued that the concept of assimilation remains valid. Brubacker rejected the 'old, analytically discredited and politically disreputable' understanding of that concept but saw value in a concept connoting a process of 
becoming similar rather than an end state of complete absorption. Assimilation is here not an involuntary process of being made similar by policy intervention but the unintended consequence of individual choices in the cultural, social, economic and political dimensions. It is moreover a process that takes individuals and groups from one mode of heterogeneity to another that is more similar to the distribution in the host population (Brubacker 2001, p. 543). In that sense, Brubacker argued, 'assimilation does not seem to be morally objectionable, analytically useless, or empirically wrong as a conceptual instrument for studying populations of immigrant origin' (Brubacker 2001, p. 534). Rather, it is appropriate to study across the different dimensions the emerging similarities, and persistent differences, with a population which is itself recognised to be diverse. So the research question is not 'how much assimilation' but in what respect, over what period of time and in relation to which reference population. We can do this regardless of whether we 'applaud or lament' the emerging similarities that are found (Brubacker 2001, p. 544).

Bommes likewise argued that it is legitimate and necessary to study the 'process of becoming similar,' as participation in organisations and fulfilling the expectations linked to them is a basic condition of economic and social life. We need to do that, however, in the context of our contemporary understanding of society: not as a single, bounded, collectivity but as functionally differentiated into different realms (such as the economy and health system), which are characterised by structural inequality and by organisations which mediate the chances of individuals participating and getting access to social resources. Nor are the systems to which people want access necessarily confined to their country of residence. Drawing on Esser (1980), he separated out four dimensions - cognitive, structural, social and identificational assimilation - in each case focusing on the acquisition of attributes, positions, relationships and identity by the migrants themselves (Bommes 2012, pp. 113-114). Bommes criticised assimilationists, however, for failing to recognise that assimilation across these dimensions does not necessarily occur at the same time or reinforce each other. Thus, while the focus remained on the process of migrants becoming similar, he emphasised both the need to clarify the point of reference in relation to which that process takes place, that of social systems and inequality, and the organisations (rather than individuals or groups) through which access is provided (Bommes 2012, pp. 111-112).

In summary, the concept of assimilation in its later forms is more complex than its ready dismissal suggests. Society is seen to be diverse, unequal and the dominant player in the process; and not bounded but embedded in transnational connections. Assimilation is not one but a series of processes across different dimensions, which do not necessarily occur at the same time, and can be analysed without assuming the desirability of any particular outcome. The focus, nevertheless, is on a process of becoming similar - far too narrow to understand the complexity of the processes at play. The migrant, moreover, is undoubtedly 'other'; the process is one of overcoming difference. While assimilation is thus not where we shall overcome the five limitations identified in recent critiques, the literature contains an early conceptual model on acculturation which does contain one further insight for a heuristic model of integration.

Lessons from acculturation studies - recognition of individual, group and societal factors Acculturation refers to the shifts in values, attitudes, behaviors and identities by 'outgroups' and by those with whom they engage. Our aim here is not to explore the 


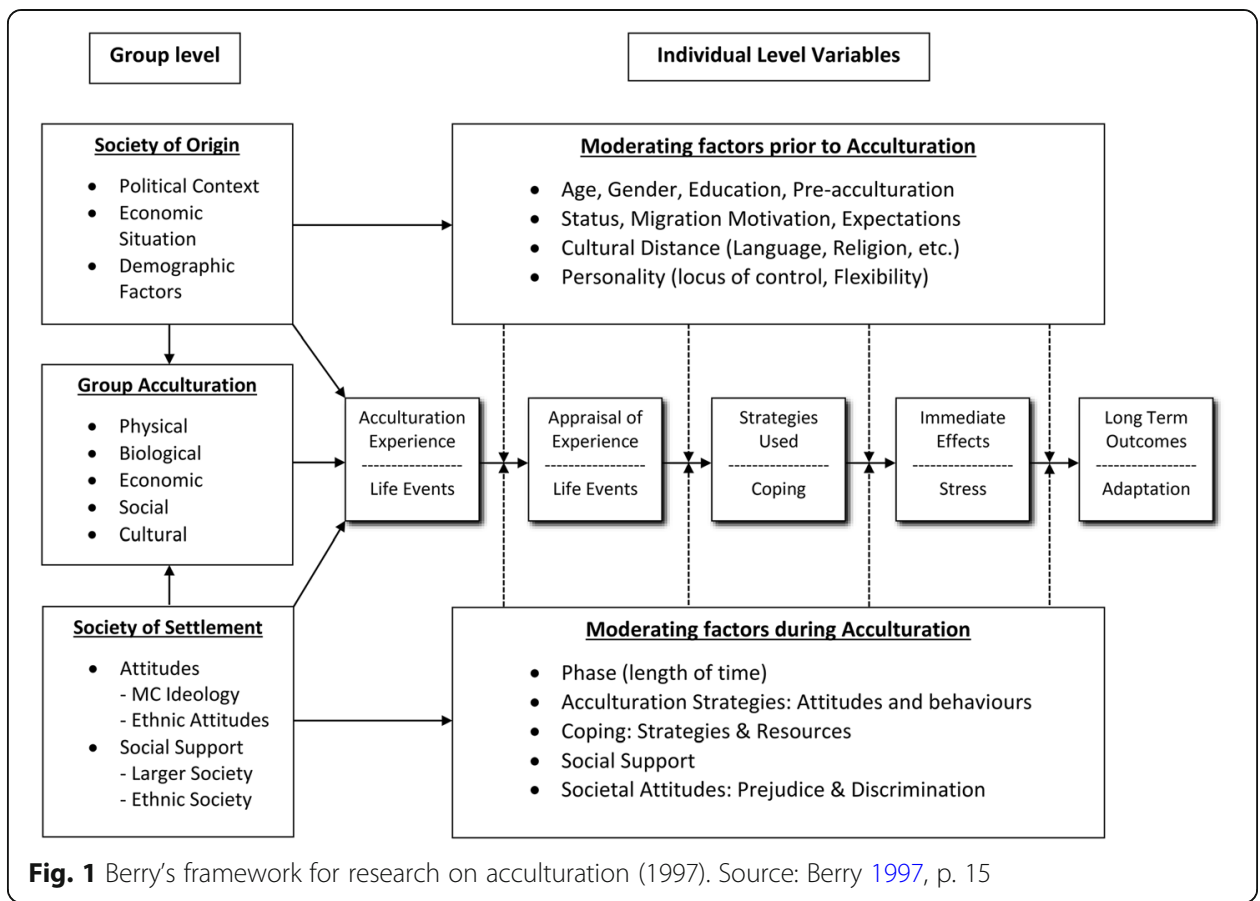

relationship between that concept and integration but more narrowly to learn from the way in which Berry sought to capture that process in a heuristic model for research purposes. ${ }^{1}$ His model, below, identifies group level (situational) variables and individual level variables, such as age and gender as well as moderating factors that exist prior to the process and those that arise during it. The centre of the diagram shows the group and individual processes as well as experiences such as life events, which impact on them: processes that are highly variable depending on the differing combinations of factors that can arise. His aim is to show the key variables that need to be attended to when carrying out studies in this field - to highlight that any study that ignores these broad classes of variables will be incomplete (Berry 1997, pp. 14-15) (Fig. 1).

Berry's approach has been influential on those researching acculturation strategies (e.g. Komisarof (2009)). Our aim here is simply to note the way in which he took account of a wide range of contextual group, individual and societal factors that shape the process: a reminder that it is not only the characteristics that individuals bring to the table which are determinative of the outcomes that emerge.

\section{Integration processes across domains}

When the sociologist Friedrich Heckmann reviewed the state of play on European integration literature a decade later it was also with the intention of providing a conceptual foundation for future research. His framework was 'social integration', here not referring solely to the social dimension of integration. Rather:

\footnotetext{
${ }^{1}$ Our thanks to Adam Komisarof at Keio University for drawing our attention to the relevance of parallel debates on acculturation to our analysis.
} 
'Social integration is understood as inclusion of individual migrants into the core institutions of the receiving society, with structural, cultural, interactive and identificative integration as dimensions of that process (Heckmann 2006, p. 2).'

Heckmann (2006) thus categorised the dimensions of integration as structural (including acquisition of rights as well as access to core institutions such as education and employment); cultural (attitudinal and behavioural change); social (relationships) and 'identificational'. Categorising the identificational dimension separately facilitates analysis of the factors which particularly affect individuals' sense of belonging and yet is not always found in later models.

Heckmann recognised that integration may take place at a different pace in each dimension (as had others before him, noted in Entzinger and Biezeveld 2003). For migrants, the feeling of belonging in the identificational dimension, for instance, may develop 'as a result of participation and acceptance' and thus come at a later stage of the integration process (Heckmann 2006, p. 17). That difference in pace may also be the case within one dimension, as in securing access to the labour market before acquiring any political rights. Temporality is thus identified as a key factor. Society is recognised to be segmented, with subcultures; adapting the concept of 'segmented assimilation' to 'segmented integration' (Heckmann 2006, p. 18). Heckmann describes the integration process as one of 'inclusion and acceptance' by the receiving society, but recognises this as an interactive process. The receiving society also has to learn new ways of interacting and adapt its institutions to their needs, a process in which it has 'much more power and prestige' and may impose barriers such as discrimination (Heckmann 2006, pp. 18-19). If the process 'succeeds', he writes, 'we talk of a society or a social system as being 'integrated' (Heckmann 2006, p. 9).

In summary, Heckmann's work is helpful, first, in its separate focus on identity. The ways in which we see ourselves, and how others see us, are fundamental to social relationships: to developing a mutual sense of belonging and entitlement, or to 'othering' and the overt racism that can accompany it. Although not determining behaviour (Jenkins 2008), identity is thus a vital dimension of integration processes, yet is often neglected or subsumed in integration models within other dimensions. Heckmann's work is also helpful in its recognition of temporality, and of the differing pace of integration processes within as well as between dimensions. It also points to the need to study integration at different levels: to identify the macro, meso and micro level factors that shape the processes that take place. While recognising that societal factors determine the scope for integration processes, however, he nevertheless describes a migrant-focussed process of 'inclusion and acceptance', and one in which there is a normative end goal: a Durkheimian integrated society.

\section{Power relations - interaction between migrants and society}

Penninx and Garcés-Mascareñas (2016) similarly developed a concept of integration as an analytical tool. Departing from Heckmann's categorisation of four dimensions of integration they identify three, in a model which allows them to shift the focal point of the analysis from migrants to their interaction with the host society. Their three 
dimensions of integration reflect the three main factors that they argue shape integration processes: legal political, socio-economic, and cultural religious (Penninx and Garcés-Mascareñas 2016, p. 14).

'We define integration', they write, as 'the process of becoming an accepted part of society (Penninx and Garcés-Mascareñas 2016, p. 14)'; a definition they see as non-normative on the grounds that it does not specify the degree of, or requirements for, acceptance. In a broader definition they refer to 'the process of settlement, interaction with the host society, and social change that follows immigration (Penninx and Garcés-Mascareñas 2016, p. 11)'; It is a model, they argue, that can be used as a tool to analyse the position of individuals and groups of immigrants at different stages of the process. Time is recognised as a key factor. Integration processes may progress at a different pace between and within dimensions and, significantly, they note that integration processes are not unidirectional: 'setbacks' may occur (Penninx and Garcés-Mascareñas 2016, p. 18-19). They illustrate their model with a diagram (Fig. 2):

The authors emphasise the extent to which processes in one dimension can condition those elsewhere, citing prejudice in the cultural dimension impacting on opportunities in the socioeconomic dimension - the example here pointing to the importance of societal factors, not only those brought by migrants themselves (Penninx and Garcés-Mascareñas 2016, p. 15). In this work the focus is on the interaction between migrants and the individuals, groups and institutions in the receiving society, with recognition that the participants in this equation are fundamentally unequal in terms of power and resources. The receiving society, they write, especially its institutional structure and reaction to newcomers, is far more decisive for the outcome of integration processes than the immigrants themselves (Penninx and Garcés-Mascareñas 2016, p. 17).

The strength of Penninx and Garcés-Mascareñas' model is in the clarity of the relationship between its constituent parts, and in its rebalancing of the focus from individual migrants to their interactions with the more powerful institutions of the receiving society; recognising that those institutions may, intentionally or not, serve to exclude. They highlight the differing pace of integration processes within as well as between

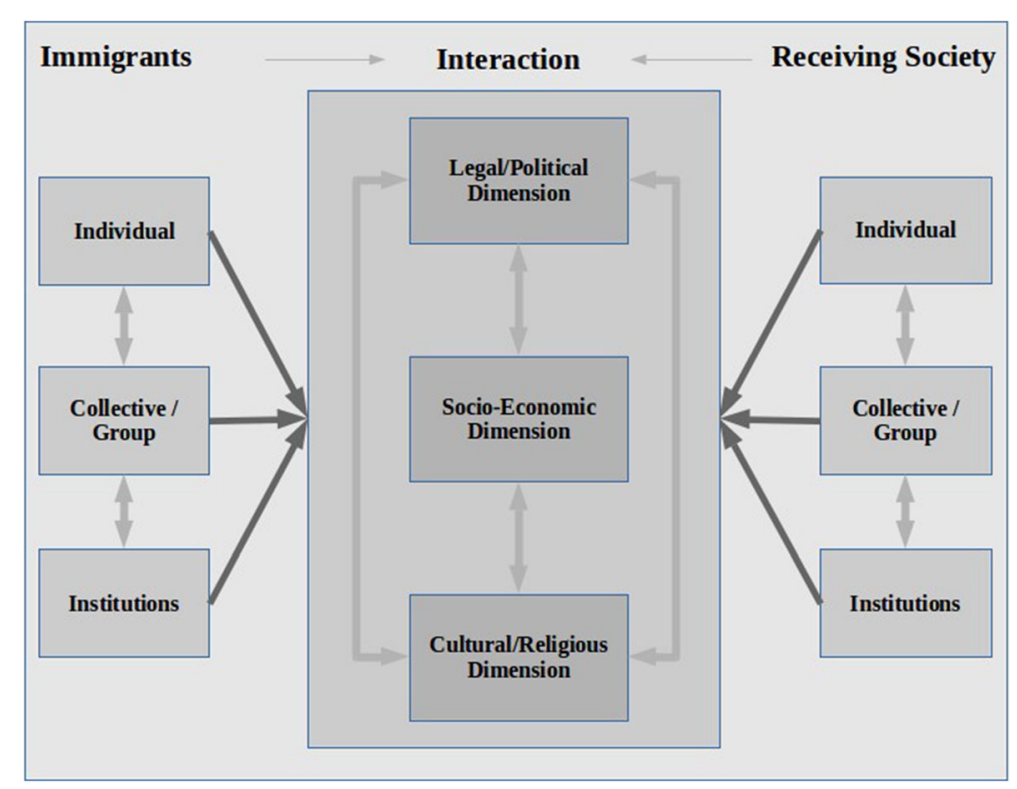

Fig. 2 Penninx and Garcés-Mascareñas' heuristic model for the empirical study of integration processes (2016). Source: Penninx and Garcés-Mascareñas (2016, p. 16 Fig. 2.1) 
dimensions; and spell out the role of policy as seeking to change those processes hence 'the study of policies is fundamentally different from the study of integration processes' (Penninx and Garcés-Mascareñas 2016, p. 19). The authors are, moreover, unusual in recognising that migrants with irregular status may equally be embarked on integration processes, albeit curtailed through limitations on their rights.

Their definition of integration as 'an accepted part of society' however does not reflect the depth of their analysis, suggesting a one way process of acceptance by the majority. 'Acceptance', the goal, is undefined and that word suggests a normative judgement of approval by the receiving society. Their reliance on a categorization of only three dimensions means that the identification domain is subsumed; and the model does not permit clarity on the extent to which processes are played out at the national or the local level. While a focus of the edited book in which they develop this model is on the need to redress the under-researched transnational dimension of integration, their model appears self-contained, without reference to transnational ties.

\section{Factors facilitating integration processes}

Although it took a policy context as its starting point, refugee settlement in the UK, Ager and Strang's conceptual framework (2008) has value in shifting the focus to the multiple social and economic factors that impact on integration processes, as well as the part played by legal rights and broader policy interventions. Rather than attempting to avoid the normative, it seeks to provide a coherent conceptual structure for considering what the key components of 'successful' integration are, bringing domains, processes and facilitators into one frame.

The resulting framework consists of four inter-related domains: Foundations (rights and citizenship - a necessary basis for integration), Facilitators (such as language, cultural knowledge and safety - which remove barriers to integration), Social Connections (bridges, bonds and links), and Means and Markers (measurable outcomes of employment, housing, education and health, which may also act as mechanisms of integration) (Fig. 3).

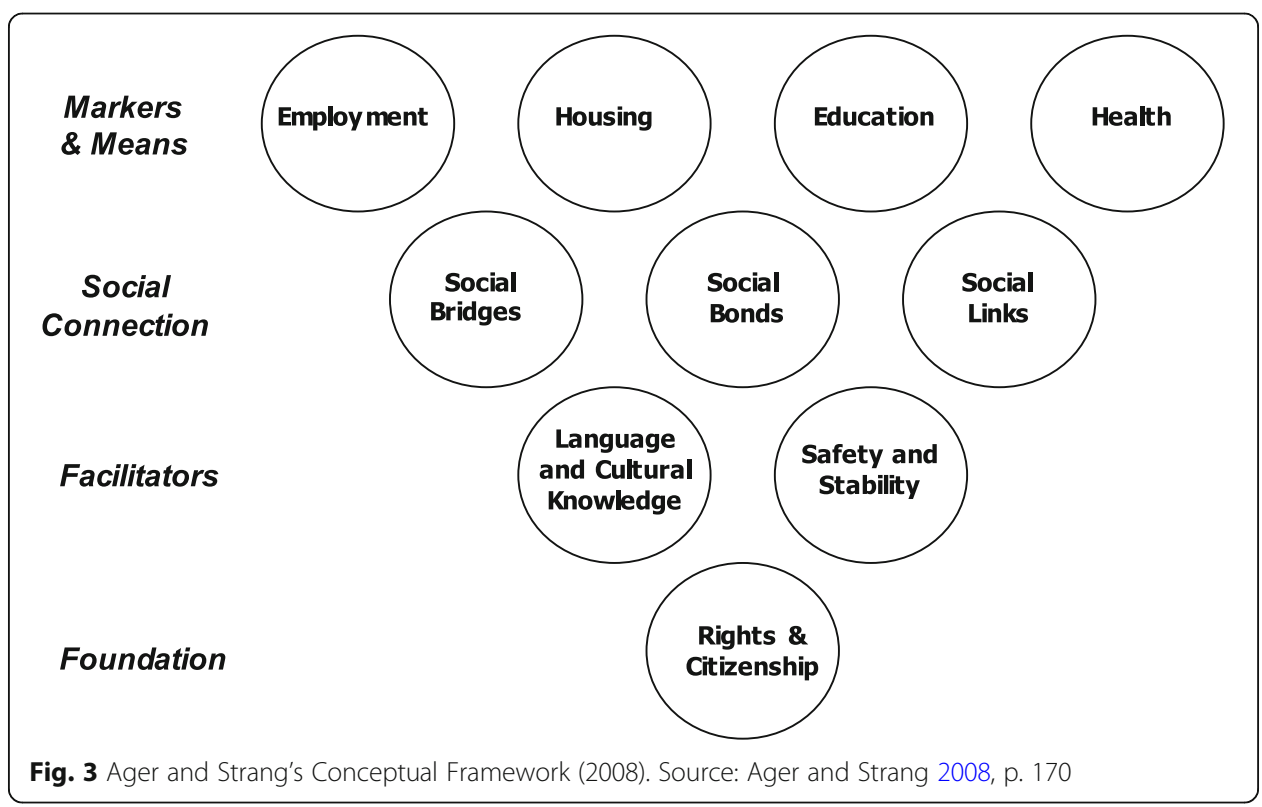


The study's basis in refugee contexts manifests in the stress on 'safety and stability', but also in the definition of 'rights and citizenship' as the foundation for integration. Whilst few would argue that lack of rights can impede integration processes, viewing them as pre-conditions may not be analytically correct. Relegating those lacking rights to a category beyond the conceptual reach of integration would be to reinforce a false binary (Anderson 2013). Finally, while Ager and Strang say that they intend to take account of transnationalism it does not figure in their diagram. Despite these caveats, the study remains an important contribution to understandings of integration as processes taking place in a multiplicity of interacting domains and levels.

\section{Integration dimensions mutually interacting}

It is useful to step back from models for a moment to see the implications of a multidimensional concept of integration when applied in research. Alba and Foner (2015), exploring facets of integration in the US and Europe, show with empirical data the extent to which integration processes in different domains can take place at a different pace, and that this varies between national contexts. They find the US to be relatively inclusive in terms of a shared sense of national identity and to fare reasonably well in political representations of migrant groups, but as having significant barriers in terms of economic inequality, residential segregation and racial discrimination. These dimensions are mutually interacting, so that factors in one domain may impact positively or negatively on another, such as the interplay between welfare systems, employment and social ties. Thus the way in which integration trajectories play out 'cannot be understood without a close examination of institutional histories and structures (Alba and Foner 2015, p. 225).' Despite their acknowledgement, however, that integration is two-way, entailing changes in wider communities (Alba and Foner 2015, p. 6), their approach has been criticized for reproducing a binary understanding of migrants and their descendants integrating into a majority ethnic mainstream (Crul 2016; Favell 2016; Statham 2016; Alba and Foner 2016).

Crul and Schneider (2010) also emphasise the significance of societal factors. In their 'comparative integration context theory', institutional structures such as the labour market and education system are the key focus. A processual perspective is necessary for the kind of comparative research required to appreciate the importance of those structures in shaping integration processes relating to migrants and their descendants; and in moving away from normative models of 'successful integration' to examine the nuanced empirical trajectories at play:

'Present state and final outcomes are the results of underlying processes over time. The analytical emphasis on process transforms the generally more sharp line between 'success' and 'failure' at the end point into a more fuzzy sequence of failures and successes'. (Crul and Schneider 2010, p. 1263)

'Failed integration' can then be seen as an indicator of obstacles to participation not of any lack of individual motivation (Crul and Schneider 2010, p. 1259). Yet retaining the language of failure suggests that the outcome of the process is being compared to a desired end goal.

Crul \& Schneider's approach is multi-level and multi-dimensional. It blends attention to macro, meso and micro levels of analysis through attention to institutions, social groups and individual factors. It explores processes in the domains of education, labour market, social relations and identification, and of culture and religion, which are seen to be 
interacting: processes in one domain impact on another, as in the way in which different education systems impact on labour market opportunities (Crul and Schneider 2010). The 'comparative integration context theory' approach thus synthesises and builds on many of the recent advances in understanding of the complexity of integration: it is processual, multi-level, multi-directional and based on an understanding of integration as taking place across several interacting domains. While its focus is on the context, it also allows for attention to individual attributes and engagements. It does not, however, go on to provide a definition or model of the complex conceptualisation of integration it portrays.

\section{Temporality: 'liquid integration'}

Our final marker in the evolution of models of integration brings attention back to issues of temporality, and the conceptualisation of society. Skrobanek and Jobst's formulation of 'liquid integration' (2019) draws on insights from processual sociology's rejection of the static understandings of society (e.g. Urry 2000) implicit in many approaches to integration. Integration, they write,

'... seems fixed, solid and straight in common integration ideologies. However, this is just a snapshot which fakes solidity, stability and site-directed convergence of social acts ... If one takes a closer look at integration, its fragility, its processual and openended dynamic character becomes visible .... (Skrobanek and Jobst 2019, p. 312).

Using Bauman's metaphor of a fluid and changing 'liquid' modernity, Skrobanek and Jobst argue that any integration into such a context must be 'conceptualised as a never-ending open process of contingent change and adjustment over the course of time' (Skrobanek and Jobst 2019, p. 313). Thus, as society changes, actors seek to adapt to those changes, and vice versa. Processes of integration therefore must be understood as not just multi-dimensional and multi-scalar, but also temporal and contingent in complex and dynamic ways.

This conceptualization of integration, drawing on contemporary sociological theory to respond to critiques of rigid models of society, deepens our understanding of its complex processual nature. The accompanying diagram, however (Fig. 4), whilst illustrating this conceptualization, may be at too abstract a level to provide obvious guidance for research design.

Fluid constraints-
Macro/Meso
Note: LI= liquid integration $=$ framing of situation, goals and practices as well as ongoing adjustment of
temporality
Fig. $\mathbf{4}$ Skrobanek and Jobst's heuristic model for simultaneous and time lag effects in the context of liquid
integration. Source: Skrobanek and Jobst (2019, p. 317).




\section{Summary: a concept in progress}

What then is the state of play in relation to concepts of integration and what remains to be addressed if we are to avoid the pitfalls its critics have identified?

Recent conceptual work has to an extent moved on from the imaginary, culturally homogenous, bounded and Durkheimian end state 'integrated society'. Integration processes are seen to be fluid processes of engagement and disengagement; processes that not only impact on the society in which they take place but are significantly shaped by its institutions and inequalities. Integration is not portrayed as a one way process of absorption but as interactive, multi-way processes of change engaging individuals, groups and institutions. Processes in each dimension, and domains within them, are recognised as proceeding at a different pace and to be mutually interacting; and from the work of Maxwell (2012) and others we know that there can be a trade-off between greater or less engagement within them. Recent work is clear that we cannot separate integration processes from the complexity of broader socio-economic processes of change, nor from their historical, spatial, temporal and transnational dimensions.

Yet we cannot say that the five weaknesses identified by integration's critics have been fully addressed. Definitions of integration retain normative concepts of desired end goals. While we now see recognition of the significant impact of societal factors, there remains a sense of 'them' and 'us' (Anderson 2013), of 'the other' on the outside coming in to society, rather than of mutually interactive processes within it. Little attention is yet paid in these concepts to the transnational dimension. Nor, we might add, is there a sense that individual engagement may be mediated by family and community networks, facilitating or impeding integration processes (Entzinger 2012, p. 401): shown decisively in our recent work on marriage migration (Charsley et al. 2020). Likewise, we see little differentiation of processes played out at the local level.

\section{Reframing 'integration': an heuristic model for the study of integration processes}

In this final section we suggest that it is possible to go further in addressing those limitations. We propose a definition of integration that captures the full dimensions of the processes at play, and a revised heuristic model (building on Spencer and Charsley 2016; Spencer 2011) that illustrates, and provides a means to study, the complex relationships between the processes and the 'effectors' that impact on them. The model draws on the many insights from the literature while seeking to avoid its limitations.

An heuristic model is not a literal depiction of processes but a tool to understand their complexity, and to operationalise in research design and analysis. It can assist researchers, when choosing research sites, subjects and data categories on which they will rely. In so doing it helps to address the limitations which critics have identified; not least to avoid reproducing the normative assumptions and 'othering' that can have damaging real world effects.

Integration, we suggest, can be defined without reference to any normative goal, or projecting any participants as 'other', as: 
'Processes of interaction, personal and social change among individuals and institutions across structural, social, cultural and civic spheres and in relation to identity; processes which are multi-directional and have spatial, transnational and temporal dimensions.'

The focus here is entirely on process. There is no concept of an end state, an 'integrated society'. The opposite of integration, is not disintegration, but the absence of processes of interaction, personal and social change. No judgement is made on the consequences of integration processes, nor lack of them. The definition, while broad to encompass the full range of processes taking place, can be operationalised, as we have done in a major empirical study, referred to below (Charsley et al. 2020).

We portray those processes as a heuristic model in Fig. 5.

The model groups the domains in which integration processes take place within five dimensions: Structural - as in participation in the labour and housing market, education and health systems; Social - as in social interaction, relationships and networks; Cultural - changing values, attitudes, behaviour and lifestyle (of all residents in this two way process); Civic and political participation - in community life and the democratic process; and Identity - the processes through which individuals of differing backgrounds may develop a shared identity and sense of belonging with the place, nation, communities and people among whom they live. That categorisation of dimensions is chosen to separate out key areas while not exceeding a reasonable number for purposes of analysis.

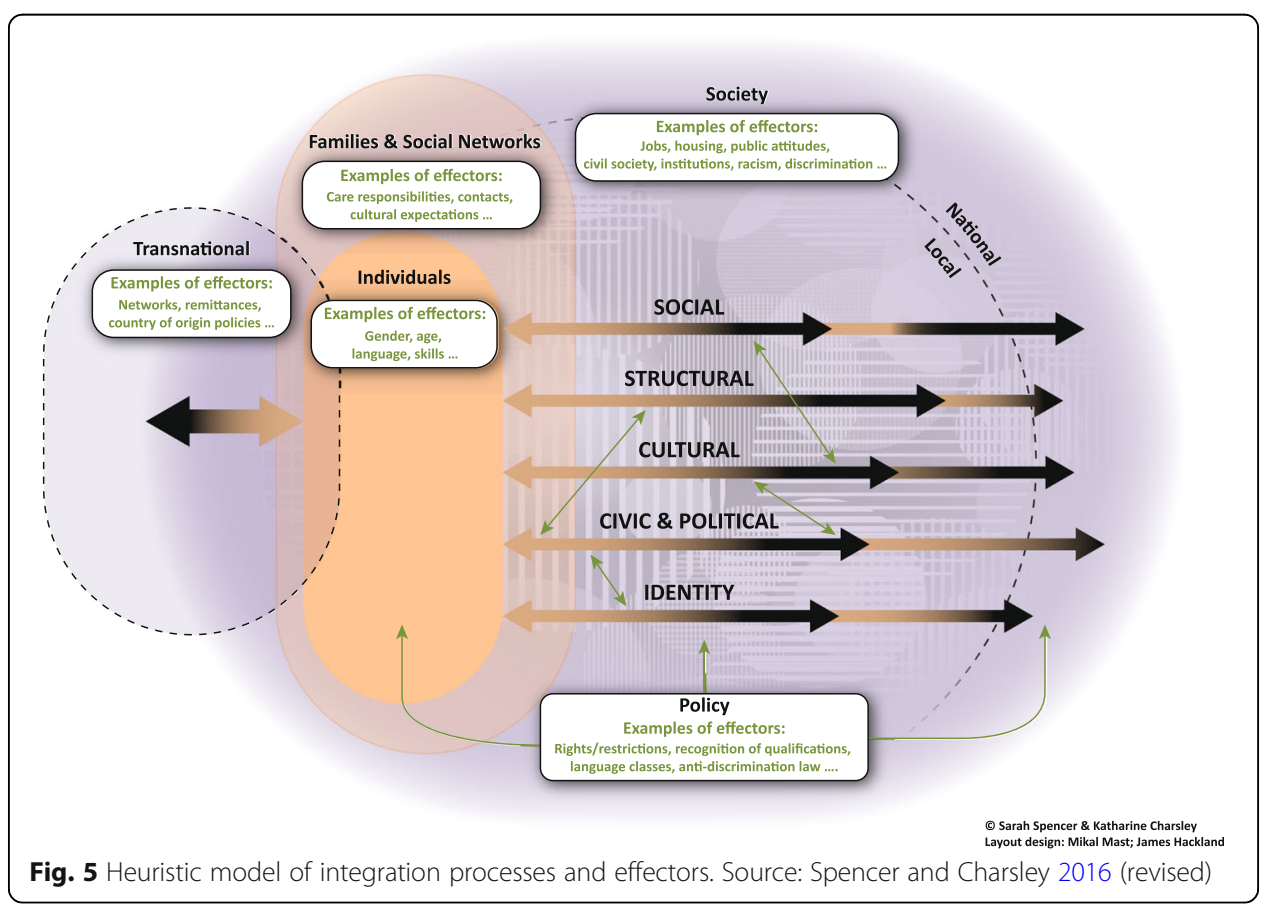


The categorisation is a heuristic device, the separation between dimensions being less evident in some contexts than others (employment in a family business blurring the boundaries, for instance; Charsley et al. 2020). Nevertheless it enables us to visualise that the processes in one dimension could develop differently to those in another; or that there could be trade-offs between engagement in one dimensions to a greater extent than another (Portes et al. 2005, p. 1013; Maxwell 2012). The diagram shows (in its textured background) that society is not homogenous, is structured and has porous borders; and that processes can take place at the micro-level of family and networks, at the wider level of local neighbourhood, at the national and the transnational level.

\section{Effectors}

We use the term 'effectors', drawn from the physical sciences, for the factors that impact on integration processes, as effectors may facilitate engagement but may also impede it. The term combines the concept of factors and of effect, the importance of which we want to highlight. The diagram shows (green text in white boxes) five sets of effectors which the literature has identified empirically as impacting on integration processes, giving illustrative examples: that is, effectors relating to individuals (such as language ability (Dustman et al. 2003); and gender (Kofman et al. 2000); families and social networks (such as care responsibilities and cultural expectations (Charsley et al. 2020); opportunity structures in society shaped by structural inequalities (such as job opportunities and education systems (Portes et al. 2005; Crul et al. 2012)); policy interventions, including restrictions on entitlements (Oliver 2013); and transnational effectors such as networks and remittances (Mügge 2016).

Crucially, the diagram illustrates (in the form of green arrows between the dimensions) that the processes within each domain can also be effectors on processes elsewhere: that is, they can impact on processes within the same dimension (as in the impact of education on engagement in the labour market) and on those in other dimensions (as in the impact of long working hours on social life). This should lead the researcher to situate their focus of study within the full range of effectors which may impact on it: to see the possibilities visually in the diagram and to investigate whether any relationship can be found.

The diagram captures the importance of scale and locality, in particular that many integration processes take place at the local level, where people live their lives; but that there can nevertheless be engagement at the national level: in the democratic process, for instance, and in relation to national identity and belonging. With differential shading within dimensions, and arrows showing differing levels of engagement at the local and national level, it conveys the relevance of time; processes of engagement taking place at a differing pace in different dimensions so that 'outcomes' may change depending on the many effectors impacting on them.

\section{Impact of using the model}

How does this model help to avoid the pitfalls that have been identified in earlier approaches? In essence, it assists the researcher to select and to contextualise their research topic, to identify research questions which do not replicate the errors, and to interrogate implicit assumptions. 
First, the definition and heuristic model identify multi-directional processes which presume no desired end goal. In policy discourse the end goal is paramount but for empirical research we should make no such assumption. The aim is to study processes taking place but our definition neither assumes individuals should engage in those processes nor makes judgement on what the outcomes should be. The model likewise does not prioritise one dimension over another: there is no presumption that the structural or cultural dimension, for instance, are of greater significance than interactions in other areas.

It remains legitimate of course to study processes in a single domain (such as the labour market). It is then necessary to acknowledge that this is only one part of the picture; that individuals are simultaneously engaged in other spheres of life that will impact on the focus of study: that neighbours or employers' perceptions of migrants' identities may, for instance, impact on their social and work opportunities (identity having been shown to be as much an interactional product of 'external' identification by others as of 'internal' self-identification (Jenkins 2008, p. 200)). Separating out identity as a dimension ensures that its impact on social attitudes and relationships in other dimensions is not overlooked.

Second, the focus is not on individual or group incorporation within an imagined, homogenous, mainstream society. Society is segmented and has porous boundaries. The focus is not on the migrant as 'other' (indeed migrants are not mentioned in the definition) but on interaction between individuals, embedded in social and institutional contexts which shape the forms those interactions take. Outcomes are the result not of one set of actors but of those interactions. Challenging though it can be methodologically, it is thus necessary to look at both sides of the interaction. This, we could say, is a 'whole society' approach, except that it is not a closed system. These are processes which can be taking place transnationally - again across the five dimensions (here illustrated by one broader arrow), at the same time as in the individual's current place of residence, without assumptions on the impact of one upon the other. In each case we could be talking here about newcomers or other residents for whom transnational connections are longstanding or newly formed.

Third, the model highlights the multiple effectors which have been shown empirically to have impacted on integration processes. These not only relate to individuals (such as gender and skills) but to the families and communities in which they are embedded, to their transnational engagement, and to the society in which they are living. Using this model it is no longer possible to study migrants or other individuals in isolation and suggest that it is solely the human and social capital they bring to the table that have shaped the integration processes in which they are engaged.

Fourth, it is clear that many integration processes take place at the local level, albeit greatly influenced by societal contexts that have in turn been shaped historically and contemporaneously by national policies. There is no denying that this is hugely complex to study - to tease out the range of factors impacting locally at any point in time, not least opportunities (or not) in the labour and housing markets or for civic engagement. If policy intervention has been a factor, it may again be difficult to separate out local policy intervention from the impact of national policies and resources; but this is the task in which we are necessarily engaged if we seek to understand the actual factors impacting on the integration processes at play. 
Finally, the model does not assume that integration policies determine 'outcomes' nor even that their impact is significant. Rather it recognises the impact of broader societal contexts (shaped in part by past policy interventions), and posits current policies as effectors which may or may not have further impact. The significance of rights, identified as one element of policy intervention, can be studied in relation to each process, not subsumed and less visible (as in some earlier models) in the structural dimension. Indicators can be identified to measure engagement (such as labour market or civic participation rates); and at the level of individuals or groups: but only with recognition that selecting these indicators are normative choices, and that 'outcomes' will change over time rather than measure an end state. Indicators can also be used to measure effectors such as levels of education or of discrimination.

Applying the model in empirical work delivers significant insights. In a recent study on the implications of transnational marriages for integration, in which the research design and analysis were grounded in this model, it was possible to tease out the multiple effectors impacting on integration processes, for migrants and for family members with no migration experience, including life course events unrelated to migration, and the impact of processes in one domain upon another (Charsley et al. 2020). 'Researching and writing about integration', we wrote then, 'is rather like untangling a complicated knot - identifying the various strands and teasing apart their relationships to each other. Pulling one strand or another first will expose particular sets of interrelationships in a different order' (Charsley et al. 2020, p. 227). From that experience we acknowledge that empirical application of a concept that recognises the complexity of multiple factors at play brings methodological challenges; as does use of data categories in national data sets (such as 'foreign born' as a proxy for migrant, regardless of date of arrival). It requires reflection on the assumptions built into those data categories, and transparency on implications when available data allows only part of the picture to be revealed.

We suggest, nevertheless, that this definition of integration and heuristic model do steer the researcher to design their study and analyse data in ways that avoid unwittingly falling into the traps identified in the first part of this article. Should we nevertheless avoid the term 'integration' to convey this concept? Is that word beyond redemption? We think it necessary to try. Any alternative term would face the same criticisms if the concept it conveyed failed to address the weaknesses that integration's critics have identified. The term integration is, moreover, still so widely used by scholars, notwithstanding those critiques, that it remains necessary to use it if we want to engage in current debates. Neglect of this topic all together, the other alternative, would leave a significant arena of social and economic life, of power imbalance and hardship, outside of the scope of serious scholarship. The focus of effort should be on interrogating the concept and addressing limitations in past use rather than on selecting, and building recognition for, the validity of a new term.

\section{Conclusion}

Empirical and theoretical insights from the rich body of research on integration have led to increasing recognition of its complexity but there remains no consensus on how it should be defined nor the processes it entails. It has moreover been the subject of harsh critiques on what we identify as five core grounds: normativity; negative 
objectification of migrants as 'other'; an outdated imaginary of society; methodological nationalism; and a narrow focus on migrants in the factors shaping integration processes. While those criticisms cannot be ignored, we have suggested that it is nevertheless necessary and possible to define integration, and to develop a model of the processes at play which help to avoid those limitations.

Having reviewed the substance of the critiques, we turned to the ways in which integration has been conceptualised to assess whether scholars who have given serious consideration to the concept have avoided the traps which the critics identified. While we found that even early models showed greater sophistication than critics might suggest, there remain major challenges to be addressed: elements of normativity in definitions of integration and in concepts of 'failure' in integration processes; 'othering' of migrants and an undue focus on the characteristics that they bring to integration processes; and a neglect of the transnational processes in which migrants and other residents can be engaged.

We drew on significant insights which that work nevertheless provides to propose a definition of integration, and strengthen our heuristic model of integration processes, to avoid those limitations. Our model identifies multi-directional processes, in domains across five related dimensions, for which there is no presumption on desired end goals. The focus is not on migrants but individuals embedded in social contexts. Multiple factors, relating to individuals, families and communities, to society and transnational engagement, impact on those processes: so that it is not credible to study individuals in isolation and suggest that it is solely the human and social capital they bring to the table that have shaped the processes in which they are engaged. It is a model in which much takes place at the local level, adding to the complexity of identifying all of the factors that impact on 'outcomes' - outcomes that are merely capturing engagement at a moment in time.

In these ways we suggest that it is possible to address the five core limitations identified by integration's critics. The concept of 'integration', we argue, is not beyond redemption. Nor do the alternative terms deployed avoid the same pitfalls. Rather, the focus of effort must be reflexive, to address the limitations of its past use; an exercise to which we hope that our definition of integration and heuristic model will make a useful contribution in an ongoing debate.

Declarations

Data sharing is not applicable to this article as no datasets were generated or analysed during the current study.

\section{Authors' contributions}

Each author made a substantial contribution to this work and read and approved the final manuscript. The authors acknowledge with thanks the helpful comments received on the draft text from colleagues in the ESRC project 'Marriage Migration and Integration', for which the conceptual model presented in this paper provided the basis of the research design and analysis; in seminars at the Centre on Migration, Policy and Society at Oxford University, and at the University of Girona, where the ideas were presented as work in progress; from Professor Rinus Penninx and Professor Peter Scholten on the penultimate draft; and from the reviewers for CMS whose comments were hugely helpful.

Funding

This work has been supported by Economic and Social Research Council (ESRC) core funding to the Centre on Migration, Policy and Society, University of Oxford (Grant No RE S-573-28-5004) and by ESRC project funding Grant Number ES/K006495/1. 


\section{Author details}

${ }^{1}$ Centre on Migration, Policy and Society (COMPAS), University of Oxford, 58 Banbury Road, Oxford OX2 6QS, UK.

${ }^{2}$ School of Sociology, Politics and International Studies, University of Bristol, Bristol, UK.

Received: 4 August 2020 Accepted: 2 February 2021

Published online: 30 April 2021

\section{References}

Ager, A., \& Strang, A. (2008). Understanding integration: a conceptual framework. Refugee Studies, 21(2), 166-191.

Alba, R. \& Foner, N. (2015). Strangers no more: The challenges of integration (Chapter 1). In Strangers no more: immigration and the challenges of integration in North America and Western Europe. Princeton University Press.

Alba, R., \& Foner, N. (2016). Strangers no more: a rejoinder. Ethnic and Racial Studies, 39(13), 2361-2369. https://doi.org/10.1 080/01419870.2016.1203450.

Anderson, B. (2013). Us and them? The dangerous politics of immigration control. Oxford: Oxford University Press.

Anthias, F., \& Pajnik, M. (2014). Contesting integration, engendering migration. Houndmills: Palgrave MacMillan.

Banton, M. (2008). The sociology of ethnic relations. Ethnic and Racial Studies., 31(7), 1267-1285. https//doi.org/10.1080/01419870701710922.

Berry, J. W. (1997). Immigration, acculturation, and adaptation. Applied Psychology: An international Review, 46(1), 5-68.

Bommes, M. (2012). Transnationalism or assimilation? In C. Boswell, \& G. D’Amato (Eds.), Immigration and social systems: Collected essays of Michael Bommes. Amsterdam: IMISCOE/Amsterdam University Press.

Brubacker, R. (2001). The return of assimilation? Changing perspectives on immigration and its sequels in France, Germany, and the United States. Ethnic and Racial Studies, 24(4), 531-548. https://doi.org/10.1080/01419870120049770.

Charsley, K., Bolognani, M., Ersanilli, E., \& Spencer, S. (2020). Marriage migration and integration. Palgrave MacMillan.

Crul, M. (2016). Strangers no more. Debunking major theoretical assumptions. Ethnic and Racial Studies, 39(13), 2325-2331.

Crul, M., \& Schneider, J. (2010). Comparative integration context theory: Participation and belonging in new diverse European cities. Ethnic and Racial Studies, 33(7), 1249-1268

Crul, M., Schneider, J., \& Lelie, F. (Eds.) (2012). The European second generation compared: Does the integration context matter? Amsterdam: Amsterdam University Press.

Dahinden, J. (2016). A plea for the 'de-migranticization' of research on migration and integration. Ethnic and Racial Studies, 39(13), 2207-2225. https://doi.org/10.1080/01419870.2015.1124129.

Dustman, C., Fabbri, F., Preston, I., \& Wadsworth, J. (2003). Labour market performance of immigrants in the UK labour market (report 05/03). London: Home Office.

Entzinger, H. (2012). The dynamics of migration and social transformations. In A. Sales (Ed.), Sociology today: social transformations in a globalizing world. Los Angeles: Sage.

Entzinger, H., \& Biezeveld, R. (2003). Benchmarking in immigrant integration. Brussels: European Commission/ERCOMER. https://ec.europa.eu/ home-affairs/sites/homeaffair/files/e-library/documents/policies/legal-migration/pdf/general/benchmarking_final_en.pdf.

Erdal, M. B., \& Oeppen, C. (2013). Migrant balancing acts: understanding the interactions between integration and transnationalism. Ethnic and Migration Studies, 39(6), 867-884.

Esser, H. (1980). Aspekte der Wanderungsgesellschaft. Darmstadt: Luchterhand.

Favell, F. (2016). Just like the USA? Critical notes on Alba and Foner's cross-Atlantic research agenda. Ethnic and Racial Studies. 39(13), 2352-2360. https://doi.org/10.1080/01419870.2016.1203447.

Fokkema, T., \& De Haas, H. (2011). The effects of integration and transnational ties on international return migration intentions. Demographic Research, 25(24), 755-782.

Gedalof, I. (2007). Unhomely homes: women, family and belonging in UK discourses of migration and asylum. Ethnic and Racial Studies., 33(1), 77-94. https://doi.org/10.1080/13691830601043513.

Hadj Abdou, L. (2019). Immigrant integration: The governance of ethno-cultural differences. Comparative Migration Studies, 7, 15. https://doi.org/10.1186/s40878-019-0124-8.

Heckmann, F. (2006). Integration and integration policies. IMISCOE network feasibility study (Final paper of INTPOL team) Bamberg: EFMS. http://www.efms.uni-bamberg.de/pdf/INTPOL\%20Final\%20Paper.pdf.

Jenkins, R. (2008). Social identity. Abingdon: Routledge.

Klarenbeek, L. M. (2019). Relational integration: A response to Willem Schinkel. Comparative Migration Studies, 7, 20. https:// doi.org/10.1186/s40878-019-0126-6

Kofman, E., Phizacklea, A., Raghuram, P., \& Sales, R. (2000). Gender and international migration in Europe. London: Taylor and Francis.

Komisarof, A. (2009). Testing a modified interactive acculturation model in Japan: American-Japanese coworker relations. International Journal of Intercultural Relations, 33(5), 319-418.

Laclau, E. (1996). Empty signifiers (Chapter 3). In Emancipation. London/New York: Verso.

Magazzini, T. (2020). Integration as an essentially contested concept: questioning the assumptions behind the National Roma Integration Strategies of Italy and Spain. In S. Hinger, \& R. Schweitzer (Eds.), Politics of (dis)integration. Cham: IMISCOE Research Series. Springer. https://doi.org/10.1007/978-3-030-25089-8_

Maxwell, R. (2012). Ethnic minority migrants in Britain and France: integration trade-offs. Cambridge: Cambridge University Press.

Mügge, L. (2016). Transnationalism as a research paradigm and its relevance for integration. In B. Garcés-Mascareñas, \& R. Penninx (Eds.), Integration processes and policies in Europe: contexts, levels and actors (pp. 109-125). Heidelberg: Springer Open.

Oliver, C. (2013). The impact of restrictions and entitlements on the integration of family migrants. Oxford: COMPAS https:// www.compas.ox.ac.uk/wpcontent/uploads/PR-2013-IMPACIM_Comparative.pdf.

Olwig, K. F., \& Paerregard, K. (2011). The question of integration: immigration, exclusion and the Danish welfare state. Newcastle upon Tyne: Cambridge Scholars Publishing

Park, R. E., \& Burgess, E. (1921). Introduction to the science of sociology. Chicago: University of Chicago Press.

Penninx, R. (2019). Problems of and solutions for the study of immigrant integration. Comparative Migrant Studies, 7, 13. https://doi.org/10.1186/s40878-019-0122-x.

Penninx, R., \& Garcés-Mascareñas, B. (2016). The concept of integration as an analytical tool and as a policy concept. In B. Garcés-Mascareñas, \& R. Penninx (Eds.), Integration processes and policies in Europe: contexts, levels and actors (pp. 11-29). Heidelberg: Springer Open http://www.springer.com/us/book/9783319216737. 
Portes, A., Fernandez-Kelly, P., \& Haller, W. (2005). Segmented assimilation on the ground: the new second generation in early adulthood. Ethnic and Racial Studies, 28(6), 1000-1040.

Rytter, M. (2010). The Family of Denmark' and 'the Aliens': Kinship Images in Danish Integration Politics. Ethnos, 75(3), $301-322$.

Rytter, M. (2018). Writing against integration: Danish imaginaries of culture, race and belonging. Ethnos, 84(4), 678-697. https:/doi.org/10.1 080/00141844.2018.1458745.

Sayad, A. (2004). The suffering of the immigrant. Cambridge: Policy Press.

Schinkel, W. (2018). Against 'immigrant integration': For an end to neocolonial knowledge production. Comparative Migration Studies, 6, 31. https://doi.org/10.1186/s40878-018-0095-1.

Schneider, J., \& Crul, M. (2010). New insights into assimilation and integration theory: Introduction to the special issue. Ethnic and Racial Studies, 33(7), 1249-1268.

Skrobanek, J., \& Jobst, S. (2019). Liquid integration? Thinking beyond conventional understanding. In S. V. Ryazantsev, M. N. Khramova, \& A. S. Maximova (Eds.), Migration as a resource for socio-economic and demographic development (pp. 307321). Moscow: Econ-Inform.

Spencer, S. (2011). Integration and citizenship. In S. Spencer (Ed.), The migration debate (vol. 6, pp. 201-245). Bristol: Policy Press. Spencer, S., \& Charsley, K. (2016). Conceptualising integration: a framework for empirical research, taking marriage migration as a case study. Comparative Migration Studies, 4(18). https://doi.org/10.1186/s40878-016-0035-X.

Statham, P. (2016). Introducing "strangers": Towards a transatlantic comparative research agenda on migrant "integration"? Ethnic and Racial Studies, 39(13), 2318-2324.

Stepick, A., \& Stepick, D. D. (2010). The complexities and confusions of segmented assimilation. Ethnic and Racial Studies, 33(7), 1149-1167. https://doi.org/10.1080/01419871003599518.

Urry, J. (2000). Sociology beyond societies: mobilities for the twenty-first century. Abingdon: Routledge.

Wieviorka, M. (2014). A critique of integration. Identities, 21(6), 633-641. https://doi.org/10.1080/1070289X.2013.828615.

\section{Publisher's Note}

Springer Nature remains neutral with regard to jurisdictional claims in published maps and institutional affiliations.

\section{Submit your manuscript to a SpringerOpen ${ }^{\circ}$ journal and benefit from:}

- Convenient online submission

- Rigorous peer review

- Open access: articles freely available online

- High visibility within the field

- Retaining the copyright to your article

Submit your next manuscript at $\boldsymbol{\nabla}$ springeropen.com 